\title{
ФИЗИКО-ХИМИЧЕСКИЕ ПОДХОДЫ К РАЗРАБОТКЕ ЭФФЕКТИВНЫХ ОРГАНОМИНЕРАЛЬНЫХ ДОБАВОК ДЛЯ БЕТОНА
}

\author{
(2018 В. Т. Перцев ${ }^{1}$, А. А. Леденев ${ }^{2}$, О. Б. Рудаков ${ }^{1}$ \\ ${ }^{1}$ Воронежский государственный технический университет, Московский пр., 14, 394026 Воронеж, Россия \\ ${ }^{2}$ Военный учебно-научный иентр Военно-воздушных сил «Военно-воздушная академия \\ им. профессора Н. Е. Жуковского и Ю.А. Гагарина», ул. Старых Большевиков, 54А, 394064 Воронеж, Россия \\ e-mail:perec_v@mail.ru
}

Поступила в редакцию 15.07.2018

\begin{abstract}
Аннотация. Представлены физико-химические подходы к разработке эффективных органоминеральных добавок для регулирования свойств бетонных смесей. Углублены представления о влиянии свойств минеральных компонентов на структурообразование цементного камня. Установлена связь результатов физико-механических испытаний цементного камня с его микроструктурой и свойствами минеральных компонентов. Показана возможность сохранения эффективности пластифицирующих добавок за счет частичного замещения поликарбоксилатного пластификатора на более доступное химическое сырье. Разработанные комплексные органоминеральные добавки позволяют модифицировать структуру цементного камня и улучшать физико-технические свойства бетона.
\end{abstract}

Ключевые слова: бетон, тонкодисперсные гетерогенные системы, межфазные границы, поверхностно-активные вещества, органоминеральные добавки.

DOI: https://doi.org/10.17308/kcmf.2018.20/580

\section{ВВЕДЕНИЕ}

В строительной индустрии актуальной научноприкладной проблемой является разработка высококачественных бетонов широкой номенклатуры, обладающих улучшенными физико-техническими и специальными свойствами. Необходимы специальные бетоны для дорожных и аэродромных покрытий, гидротехнических сооружений, термостойкие бетоны для предприятий с высокотемпературными технологическими процессами. Одним из направлений получения высококачественных бетонов является применение комплексных полифункциональных органоминеральных добавок (ОМД), включающих органические и минеральные компоненты [1-6]. Задачи повышения эффективности применения ОМД в бетонах требуют дальнейшего экспериментального изучения и теоретического осмысления с применением физико-химических подходов. Необходимо не только расширять сырьевую базу компонентов ОМД за счет использования минеральных и химических добавок различной природы, но и разрабатывать химические технологии их получения и применения в производстве бето- нов, изучать механизм их действия на гетерогенные системы, образующие бетон.

При оценке эффективности минеральных компонентов ОМД, как правило, тонкодисперсных, в основном учитывается «химический» фактор, обусловленный химико-минералогическим составом и активностью ОМД, а также «физический» фактор, связанный с получением плотных структур цементного камня. Эти факторы строительные материаловеды обобщают под термином «баланс сил», понимая, что механизм действия минеральных компонентов на гетерогенную систему бетона чрезвычайно сложен и отличается многофункциональностью и разнонаправленностью. Эмпирически варьируя компоненты ОМД, общий состав бетонной смеси, материаловеды смещают «баланс сил» в ту или иную сторону и фиксируют технические характеристики образовавшегося материала. Из-за высокой поверхностной активности ОМД в смесях их включающих реализуются межчастичные и межфазные взаимодействия, которые не позволяют применять для исследования процессов структурообразования модели плот- 
ных упаковок, характерных для грубодисперсных гетерогенных систем. В тонкодисперсных системах в результате проявления молекулярно-электростатических сил и капиллярно-пленочных взаимодействий характерными процессами являются агрегирование, самоорганизация и формирование фрактально-кластерных структур [7]. Особенностью фрактально-кластерных структур является их самоподобие, проявляющееся на микро- и мезоуровнях. Оно оказывает существенное влияние на процессы раннего коагуляционного структурообразования, а также схватывания и твердения. В таких системах эффективность минеральных компонентов во многом будет определяться факторами, характеризующими структуру и свойства поверхности частиц, которые зачастую не учитываются строительными материаловедами, а именно: форма и шероховатость, природа поверхности, наличие активных центров и др. Выявление закономерностей формирования фрактально-кластерных структур позволяет связать структурные характеристики цементных систем с их физико-механическими свойствами. Дополнительного рассмотрения требуют вопросы количественной оценки таких структур с учетом характеристик и свойств минеральных компонентов. Что касается химических компонентов ОМД, то в настоящее время существует большой ассортимент промышленно выпускаемых химических добавок поверхностноактивных веществ (ПАВ) на основе нафталинформальдегидных, поликарбоксилатных соединений и др. Однако для повышения эффективности химических добавок в составе ОМД перспективным направлением является использование и других химических соединений, а также применение комплексных химических добавок. Физико-химические подходы в исследованиях в данной области знаний позволят целенаправленно подойти к выбору компонентов ОМД для регулирования свойств бетонных смесей, углубить представления о влиянии физико-химических свойств минеральных компонентов на эффективность их взаимодействия с компонентами бетонной смеси, понять механизм их действия. В конечном итоге это позволит расширить ассортимент ОМД для придания бетонам специальных свойств.

Целью работы является разработка и реализация концептуальных физико-химических подходов к исследованию и оценке эффективности ОМД для регулирования свойств бетонных смесей и бетонов.

\section{МЕТОДОЛОГИЯ ИССЛЕДОВАНИЙ И СЫРЬЕВЫЕ МАТЕРИАЛЫ}

Многообразие применяемых минеральных компонентов и факторов, определяющих их эффективность в составе ОМД, обуславливает необходимость разработки классификационных групп по различным признакам (табл. 1). В ходе анализа представленных классификационных групп минеральных компонентов была разработана система факторов, определяющих их эффективность в составе комплексных ОМД (рис. 1), которая позволит систематизировать минеральные компоненты и определить роль факторов в явлениях и процесcax, протекающих в цементных системах. Выявление факторов, влияющих на формирование структуры и свойства цементных систем на различных этапах структурообразования, их комплексная количественная и качественная оценка необходима для определения взаимного сочетания и выявления синергетического эффекта компонентов ОМД при разработке новых эффективных ОМД, позволяющих прогнозировать и регулировать свойства бетонных смесей и бетонов.

При выборе минеральных компонентов ОМД из групп, приведенных в табл. 1, с целью расширения сырьевой базы этих компонентов в работе остановились на характерных представителях материалов доступных для Центрально-Черноземного и Южного регионов Российской Федерации. Это природные материалы осадочного и вулканического происхождения: кварцевый песок, известняк, вулканический туф, вулканический пепел, биокремнезем; а также техногенные материалы: гранулированный шлак - отход металлургического производства; золошлаковые отходы ТЭЦ. Дисперсность минеральных компонентов составляла $100-700 \mathrm{~m}^{2} /$ кг, для биокремнезема - $20000 \mathrm{~m}^{2} / \kappa г$, дозировка минеральных компонентов $10 \%$ от массы цемента. Химико-минералогический состав применяемых минеральных компонентов представлен в табл. 2, 3.

В качестве исследуемых химических компонентов ОМД применяли пластификаторы различной природы и механизма действия. Это комплексная пластифицирующая воздухововлекающая добавка «Кратасол ПФМ» на основе полиметилен- $\beta$-нафталинсульфонатов и воздухововлекающих компонентов. Для данной добавки определяющую роль в механизме пластифицирования цементных систем выполняют силы электростатического отталкивания, проявляющиеся в результате адсорбции моле- 
Таблица 1. Классификационные группы минеральных компонентов для ОМД

[Table 1. Classification groups of mineral components for organomineral additives]

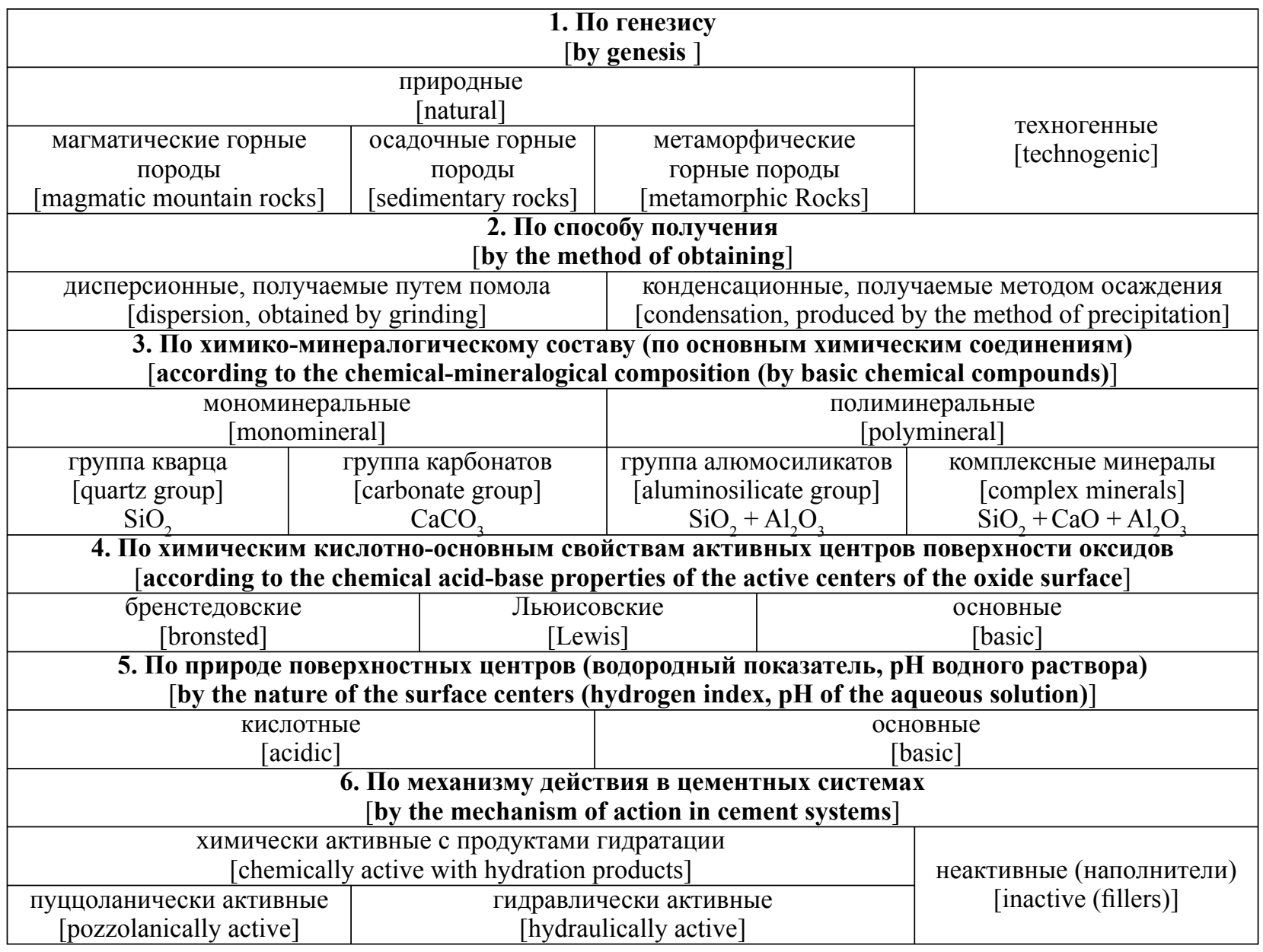

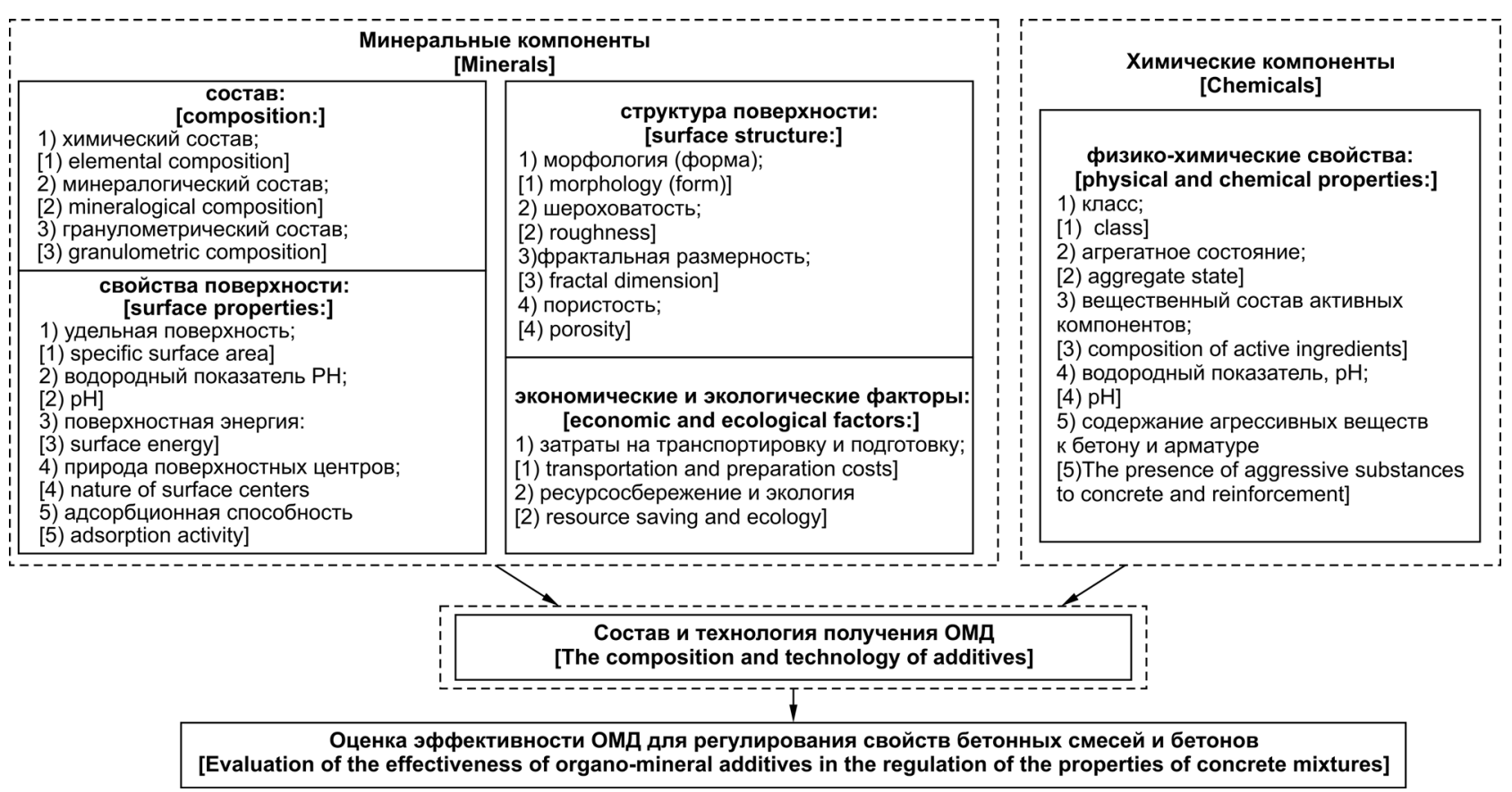

Рис. 1. Система факторов, определяющих эффективность ОМД

[Fig. 1. System of factors determining the effectiveness of organomineral additives] 
Таблица 2. Химический состав природных минеральных компонентов ОМД

[Table 2. Chemical composition of natural mineral components of organomineral additives]

\begin{tabular}{|c|c|c|c|c|c|c|c|c|}
\hline \multirow[b]{2}{*}{$\begin{array}{l}\text { Материал } \\
\text { [Material] }\end{array}$} & \multicolumn{8}{|c|}{$\begin{array}{c}\text { Содержание компонентов, масс. \% } \\
\text { [Content of components, wt. \%] }\end{array}$} \\
\hline & $\mathrm{SiO}_{2}$ & $\mathrm{CaO}$ & $\mathrm{Al}_{2} \mathrm{O}_{3}$ & $\mathrm{Fe}_{2} \mathrm{O}_{3}+\mathrm{FeO}$ & $\mathrm{MgO}$ & $\mathrm{Na}_{2} \mathrm{O}+\mathrm{K}_{2} \mathrm{O}$ & $\mathrm{SO}_{3}$ & $\begin{array}{c}\text { потери при } \\
\text { прокаливании } \\
\text { [losses at } \\
\text { calcination] }\end{array}$ \\
\hline $\begin{array}{l}\text { кварцевый песок } \\
\text { [quartz sand] }\end{array}$ & 97.6 & 0.7 & 1.3 & 0.4 & - & - & - & - \\
\hline $\begin{array}{l}\text { известняк } \\
\text { [limestone] }\end{array}$ & 1.0 & 55.0 & 0.2 & 0.4 & 0.2 & - & 0.2 & 43.0 \\
\hline $\begin{array}{c}\text { вулканический туф } \\
\text { [volcanic tuff] }\end{array}$ & 74.0 & 1.3 & 14.3 & 1.8 & 1.3 & 5.2 & 0.1 & 2.0 \\
\hline $\begin{array}{c}\text { вулканический пепел } \\
\text { [volcanic ash] }\end{array}$ & 73.0 & 1.2 & 13.5 & 1.5 & 1.1 & 7.6 & 0.1 & 2.0 \\
\hline $\begin{array}{c}\text { биокремнезем } \\
\text { (обработанный } \\
\text { диатомит) } \\
\text { [biokremnezem } \\
\text { (treated diatomaceous)] }\end{array}$ & 88.0 & - & 7.1 & 2.8 & 0.8 & 1.3 & - & - \\
\hline
\end{tabular}

Таблица 3. Химический состав техногенных минеральных компонентов ОМД

[Table 3. Chemical composition of technogenic mineral components of additives]

\begin{tabular}{|c|c|c|c|c|c|c|c|c|c|c|c|}
\hline \multirow[b]{2}{*}{$\begin{array}{l}\text { Материал } \\
\text { [Material] }\end{array}$} & \multicolumn{11}{|c|}{$\begin{array}{c}\text { Содержание компонентов, масс. \% } \\
\text { [Content of components, wt. \%] }\end{array}$} \\
\hline & $\mathrm{SiO}_{2}$ & $\mathrm{CaO}$ & $\mathrm{Al}_{2} \mathrm{O}_{3}$ & $\begin{array}{c}\mathrm{Fe}_{2} \mathrm{O}_{3}+ \\
\mathrm{FeO}\end{array}$ & $\mathrm{MgO}$ & $\begin{array}{c}\mathrm{Na}_{2} \mathrm{O}+ \\
\mathrm{K}_{2} \mathrm{O}\end{array}$ & $\mathrm{SO}_{3}$ & $\mathrm{~S}$ & $\mathrm{TiO}_{2}$ & $\mathrm{P}_{2} \mathrm{O}_{5}$ & $\begin{array}{c}\text { потери при } \\
\text { прокаливании } \\
\text { [losses at } \\
\text { calcination] }\end{array}$ \\
\hline $\begin{array}{c}\text { граулированный } \\
\text { шлак } \\
\text { [granulated slag] }\end{array}$ & 38.1 & 44.5 & 10.7 & 0.5 & 5.4 & - & - & 0.8 & - & - & - \\
\hline $\begin{array}{c}\text { золошлаковые } \\
\text { отходы ТЭЦ } \\
\text { [ash-and-slag } \\
\text { wastes of thermal } \\
\text { power station] }\end{array}$ & 62.7 & 7.0 & 18.5 & 8.4 & 1.0 & 0.4 & 0.9 & - & 0.2 & 0.1 & 0.8 \\
\hline
\end{tabular}

кул ПАВ на поверхности частиц. Также применяли пластифицирующую добавку «Melflux 2651F» на основе поликарбоксилатов, для которой преобладающим в механизме действия является «стерический» эффект отталкивания. Молекулы поликарбоксилатных пластификаторов имеют главную цепочку (основу) с отрицательными зарядами, которая адсорбируется на цементной частице, и незаряженные боковые цепочки (рис. 2).

Именно боковые цепочки создают адсорбционную объемную защитную оболочку вокруг частиц твердой фазы, предотвращая агрегирование частиц цемента и способствуя их взаимному «стерическому» отталкиванию. Благодаря особенностям стро- ения поликарбоксилаты обладают высоким пластифицирующим и водоредуцирующим действием. Однако их практическим недостатком является относительно высокая стоимость. Ранее проведенные теоретические и экспериментальные исследования показали возможность повышения эффективности поликарбоксилата «Melflux 2651F» за счет его частичного замещения, на 20-30 \%, в составе комплексной (бинарной) химической добавки на полиэтиленгликоль ПЭГ-2000, который имеет химическое строение, идентичное боковым цепям «Melflux 2651F»[8, 9]. Это позволило снизить дозировку дорогостоящего компонента с максимальным сохранением эффективности действия в цементных системах. 
a)

$$
\begin{aligned}
& \text { Поликарбоксилат } \\
& \text { (Polycarboxylate) }
\end{aligned}
$$

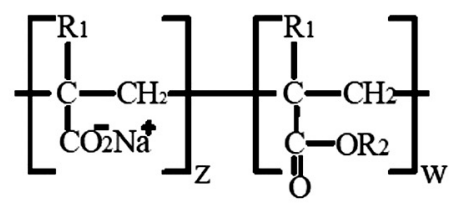

$\left.\mathrm{R}_{1}=\mathrm{CH}_{3}, \mathrm{H} ; \quad \mathrm{R}_{2}=\mathrm{HO}-\mathrm{CH}_{2}-\mathrm{CH}_{2}-\mathrm{O}\right\}_{\mathrm{X}}^{\mathrm{H}}$ b)

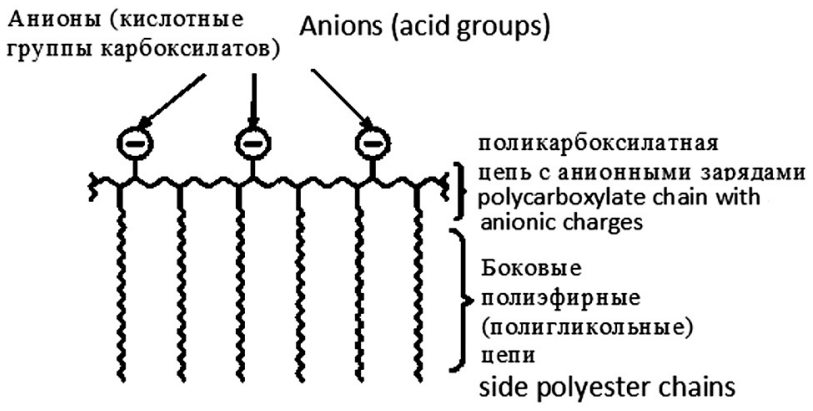

Рис. 2. Структурная формула $(a)$ и строение молекулы $(b)$ поликарбоксилатного пластификатора

[Fig. 2. Structural formula $(a)$ and structure of the $(b)$ polycarboxylate plasticizer molecule]

\section{РЕЗУЛЬТАТЫ И ИХ ОБСУЖДЕНИЕ}

Эффективность минеральных компонентов в составе ОМД во многом обусловлена степенью их дисперсности. С увеличением дисперсности повышается активность, роль поверхностных сил становится определяющей, при этом существенно меняется структура и свойства систем. На примере молотого кварцевого песка установлено, что с увеличением дисперсности частиц, начиная с $100 \mathrm{~m}^{2} / \kappa \Gamma$ и выше, снижается плотность свободноуложенных сухих систем (рис. 3). В результате процессов самоорганизации дисперсная система, представленная отдельными частицами, формируется в виде агрегатов, которые образуют «цепочную» фрактальнокластерную микроструктуру с высокой пористостью и пустотностью.

Из рис. 3 видно, что для минеральных компонентов увеличение дисперсности свыше $700 \mathrm{~m}^{2} / \kappa г$ может быть не эффективно за счет резкого снижения плотности, повышения водопотребности систем, а также больших энергозатрат на помол. В последующих исследованиях использовали минеральные компоненты для ОМД с $S_{\text {уд }}=700 \mathrm{~m}^{2} /$ кг. Грану-

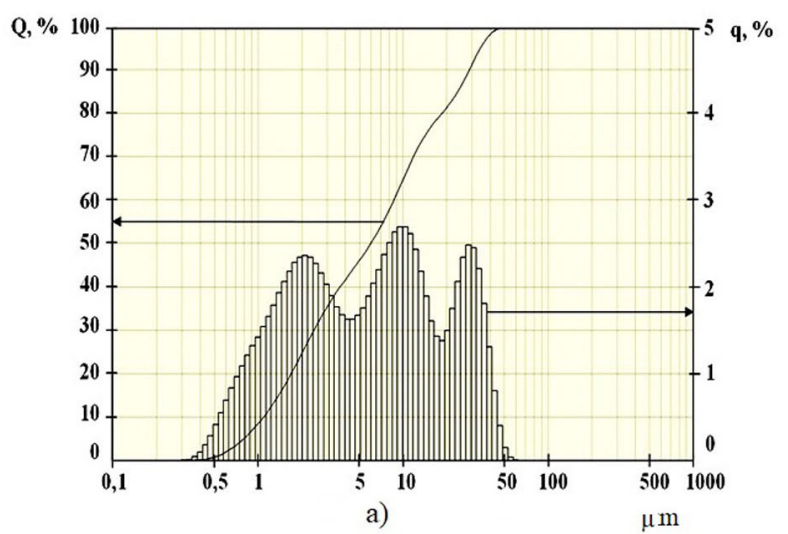

лометрический анализ показал, что применяемые минеральные компоненты при данной тонкости помола характеризуются полидисперсным распределением частиц размером от 0.5 до 50 мкм (рис. 4). Графики распределения частиц имеют схожий ха-

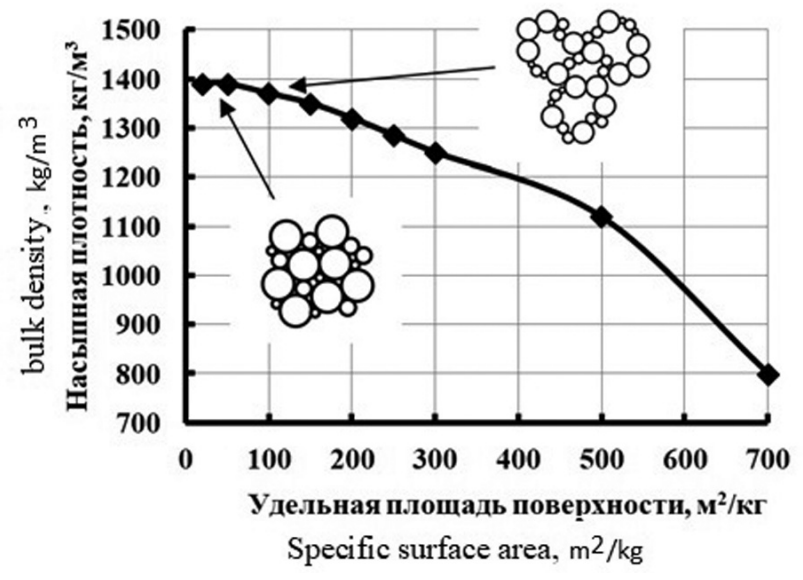

Рис. 3. Влияние дисперсности частиц молотого песка на структуру и плотность свободноуложенной сухой системы

[Fig. 3. Influence of the dispersion of particles of ground sand on the structure and density of a free-laid dry system]

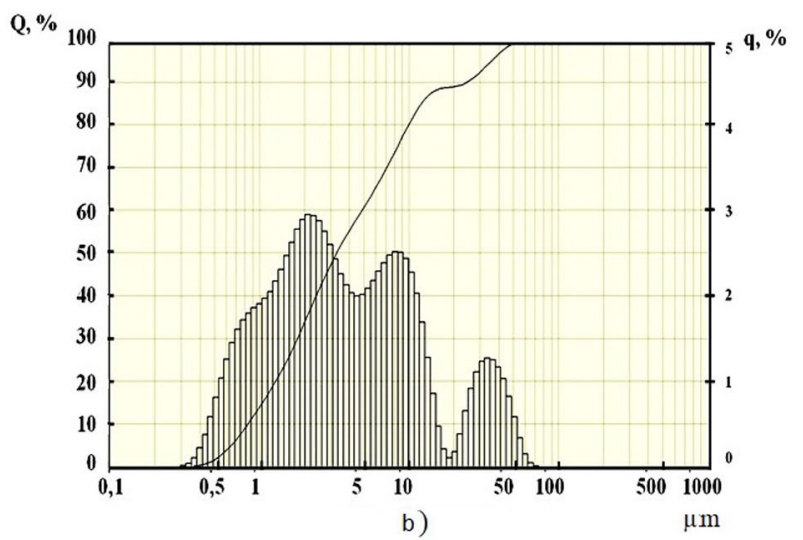

Рис. 4. Гранулометрический состав минеральных компонентов дисперсностью $S_{\text {уд }}=700 \mathrm{~m}^{2} /$ кг: a) молотый песок; $b$ ) молотый известняк

[Fig. 4. Granulometric composition of mineral components with a dispersion of $S_{\mathrm{d}}=700 \mathrm{~m}^{2} / \mathrm{kg}: a$ ) ground sand; $b$ ) ground limestone] 
рактер с несущественными различиями, обусловленными их структурой и свойствами.

Электронно-микроскопические исследования показали, что дисперсные минеральные системы имеют агрегированную фрактально-кластерную структуру, отличительным свойством которой является самоподобие на микро- и мезоуровнях (рис. 5). Микроструктура минеральных дисперсных систем во многом определяется фрактальной структурой и свойствами поверхности отдельных частиц. Установлено, что тонкодисперсные частицы осадочных горных пород имеют существенные отличия: частицы молотого кварцевого песка имеют характерную угловатую остроугольную форму поверхности в отличие от поверхности частиц известняка, отличающихся микрозернистостью и округлой формой (рис. $5 a, b)$. Частицы вулканических горных пород туфа и пепла имеют ярко выраженную кристалли-

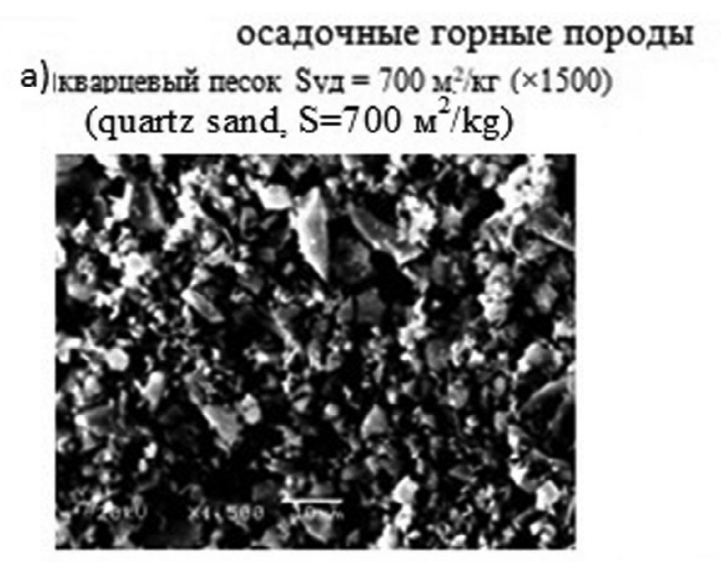

вулканнческне горные породы

\section{(sedimentary rock)}

b) нзвестняк $\mathrm{Syz}=700 \mathrm{M}^{2} / \mathrm{kr}(\times 2000)$ (limestone, $\mathrm{S}=700 \mathrm{~m}^{2} / \mathrm{kg}$ )

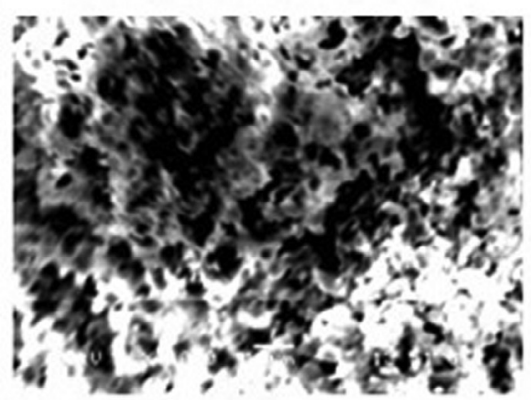

(volcanic rock)

d) nener Syд $=700 \mathrm{~m}^{2} / \mathrm{kr}(\times 2000)$ (ashes, $\mathrm{S}=700 \mathrm{~m}^{2} / \mathrm{kg}$ )

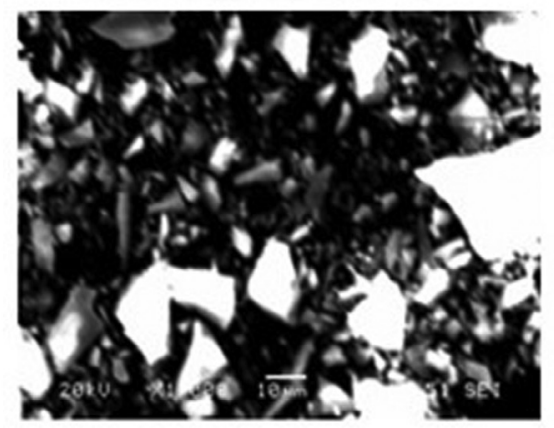

техногенные матерналы (technogenic materials)

e) гранштах (granulated slag, $\mathrm{S}=700 \mathrm{~m}^{2} / \mathrm{kg}$ )

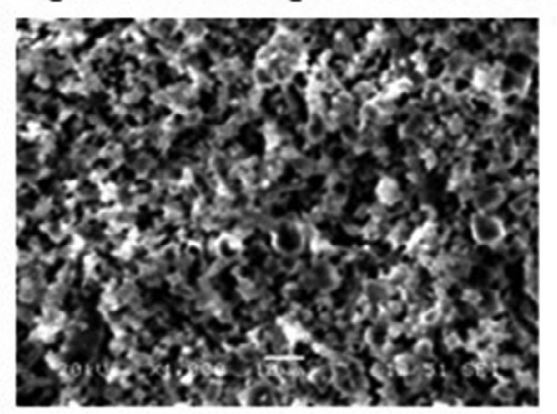

g) зола ТЭЦ в исходвом состовния $\mathrm{SvI}=420 \mathrm{x}^{2} / \mathrm{kr}(\times 2000)$

(ash of thermal power station, $S=420 \mathrm{~m}^{2} / \mathrm{kg}$ )

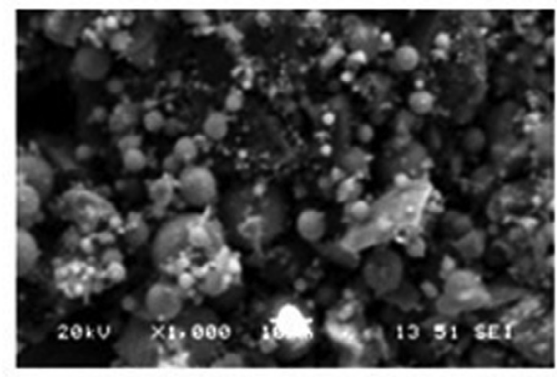

Рис. 5. Микроструктура сухих минеральных компонентов различного генезиса [Fig. 5. Microstructure of dry mineral components of various genesis] 
ческую остроугольную форму поверхности, обусловленную особенностями формирования горных пород и последующим выветриванием (рис. $5 c, d$ ). Структура поверхности частиц техногенных материалов, полученных различными способами, также имеет существенные отличия (рис. $5 e, g$ ): тонкодисперсный гранулированный шлак имеет округлую форму поверхности, характерной особенностью исходных частиц золошлаковых отходов ТЭЦ (до помола $S_{\text {уд }}=420 \mathrm{~m}^{2} /$ кг) является их сферическое строение. При помоле золы сферы частично разрушаются с образованием частиц имеющих высокоразвитую внутреннюю и внешнюю поверхность (рис. 6).

При введении минеральных компонентов происходит разрастание и объединение всего объема цементной системы с формированием непрерывного перколяционного фрактального кластера, определяющего свойства цементного теста и камня. Минеральные компоненты и их агрегаты являются важным элементом структуры цементной системы, оказывая полифункциональное влияние, как на этапе раннего структурообразования, так и на этапе кристаллизационного структурообразования - схватывания и твердения. На раннем этапе, когда пуццоланическая и гидравлическая активность, обусловленная их химико-минералогических составом, не оказывает значительного влияния на свойства цементной системы, определяющую роль в процессе структурообразования играют характеристики поверхности частиц твердой фазы. Роль химических процессов в значительной степени проявляется на этапе схватывания и твердения.
Результаты физико-механических испытаний показали, что исследованные минеральные компоненты, оказывая многофункциональное влияние на процессы структурообразования, способствуют повышению прочности цементного камня (рис. 7). Это позволяет эффективно использовать их в составе ОМД.

Различие в эффективности минеральных компонентов обусловлено различными факторами, влияющими на процессы структурообразования цементного камня. Наибольшая прочность цементного камня зафиксирована при использовании химически активных алюмосиликатных и кремнеземистых материалов: туфа, пепла, кварцевого песка. Данные материалы, содержащие значительное количество $\mathrm{SiO}_{2}$, обладают высоким пуццоланическим действием, проявляющемся на этапе кристаллизационного структурообразования - схваты-
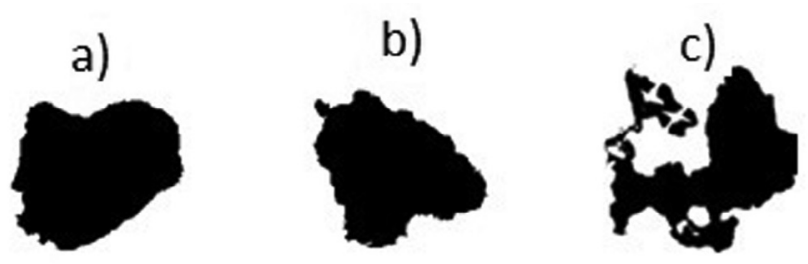

Рис. 6. Вид проекции молотых частиц (на мезоуровне): $a$ ) песка; $b$ ) известняка; $c$ ) золы; $S_{\text {уд }}=500 \mathrm{~m}^{2} /$ кг, $(\times 400)$

[Fig. 6. The projection of the projection of ground particles (at the meso level): $a$ ) sand; $b$ ) limestone; $c$ ) ash; $\left.S_{\mathrm{d}}=500 \mathrm{~m}^{2} / \mathrm{kg},(\times 400)\right]$

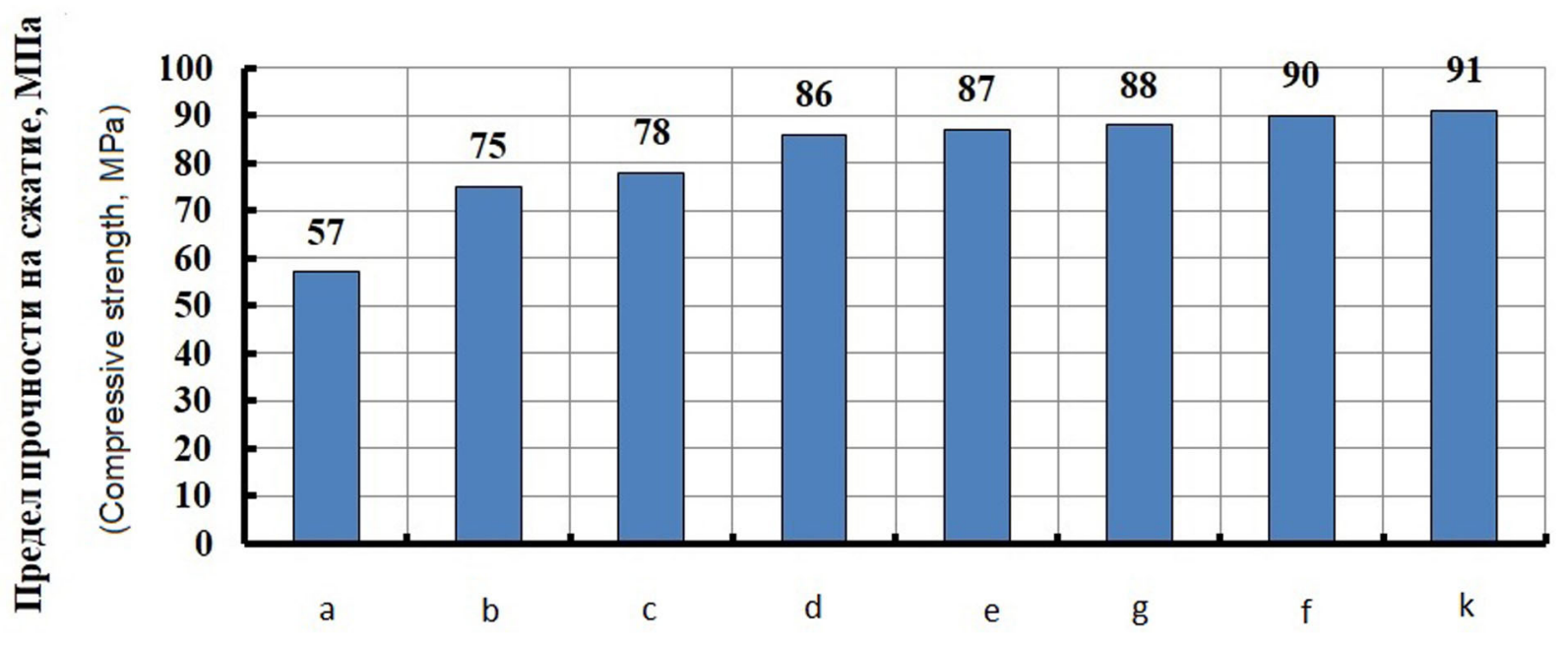

Рис. 7. Влияние минеральных компонентов на прочность цементного камня (дозировка 10 \% от массы цемента, дисперсность компонентов $700 \mathrm{~m}^{2} / \kappa г$, для биокремнезема - $20000 \mathrm{M}^{2} / \kappa г$ )

[Fig. 7. Influence of mineral components on cement stone strength (10\% of cement mass, dispersibility of components $700 \mathrm{~m}^{2} / \mathrm{kg}$, biosilica $\left.\left.-20000 \mathrm{~m}^{2} / \mathrm{kg}\right)\right]$ 
вания и твердения. Эффективность биокремнезема, обладающего более высокой дисперсностью $S_{\text {уд }}=20000 \mathrm{~m}^{2} /$ кг и химической активностью, сопоставима с другими кремнеземистыми минеральными компонентами. Это, по-видимому, обусловлено формированием более разветвленной фрактально-кластерной структурой с низкой плотностью, которая сохраняется в процессе твердения цементного камня.

Использование гранулированного шлака (граншлака) также позволяет значительно повысить прочность цементного камня до 87 МПа за счет содержания в его составе гидравлически активных минералов. Меньшую эффективность, даже по сравнению с инертными карбонатными горными породами - известняками, показала зола ТЭЦ, несмотря на ее химическую активность, обусловленную содержанием $\mathrm{SiO}_{2}$ до 60 \%. Такое проявление может быть обусловлено характеристиками поверхности частиц золы, которые после помола имеют развитую внутреннюю и внешнюю поверхность с более разветвленной и менее плотной структурой.

В ходе реализации технологии получения ОМД были разработаны комплексные добавки с различными видами минеральных и химических компонентов (см. табл. 4). Уставлено, что эффективность ОМД обусловлена совместным действием химического компонента, определяющего пластифицирующее и водоредуцирующее действие, и минерального компонента, участвующего в формировании микроструктуры цементного камня. Наибольший водоредуцирующий эффект до 44 \% и прочность цементного камня были получены при использовании в составе ОМД бинарной химической добавки «Melflux 2651F + ПЭГ 2000» при замене $25 \%$ «Melflux 2651F» на более доступный химический компонент «ПЭГ 2000» (табл. 4).

Данные электронно-микроскопических исследований показали связь результатов физико-механических испытаний цементного камня с его микроструктурой (рис. 8, 9). Так, использование ОМД, содержащей в качестве минерального компонента молотый песок (рис. 8c), способствует формированию более плотной и однородной структуры цементного камня на микроуровне по сравнению с цементным камнем без добавок (рис. $8 a$ ) и с другими минеральными компонентами, например, золы ТЭЦ (рис. 8b). Полученные данные коррелируют с плотностью и прочностью цементного камня (см. табл. 4).

Применение ОМД, включающих «Кратасол ПФМ» и минеральных компонентов на основе вулканических горных пород - пепла, туфа, также позволяет модифицировать микроструктуру и улучшать физико-технические характеристики цементного камня (рис. 9). Установлено наличие более плотной микроструктуры цементного камня (рис. 9b), что соотносится с прочностью. Кроме того, за счет входящих в состав ОМД воздухововлекающего ПАВ формируется благоприятная с точки зрения повышения морозостойкости система равномерно распределенных условно-замкнутых микропор 50-100 мкм (рис. 9c). Тем самым, создается объем пор, необходимый для проникновения воды под давлением при замерзании.

Таблица 4. Свойства цементного теста и камня с ОМД

[Table 4. Properties of cement paste and stone with organomineral additives]

\begin{tabular}{|c|c|c|c|c|c|c|}
\hline \multirow{2}{*}{ No. } & \multicolumn{2}{|c|}{$\begin{array}{c}\text { Вид и дозировка компонентов ОМД } \\
\text { [Type and dosage of components] }\end{array}$} & \multirow{2}{*}{$\begin{array}{c}\text { Водоцементное } \\
\text { отношение } \\
\text { [Water-cement } \\
\text { ratio] }\end{array}$} & \multirow{2}{*}{\begin{tabular}{|c|} 
Водоредуцирую- \\
щий эффект, \% \\
[Water-reducing \\
effect, \%]
\end{tabular}} & \multirow{2}{*}{ 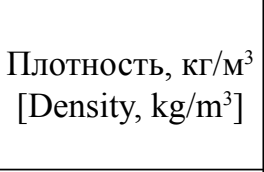 } & \multirow{2}{*}{$\begin{array}{l}\text { Прочность на } \\
\text { сжатие, МПа } \\
\text { [Compressive } \\
\text { strength, MPa] }\end{array}$} \\
\hline & $\begin{array}{c}\text { химический } \\
\text { [chemical] }\end{array}$ & $\begin{array}{c}\text { минеральный } \\
\text { [mineral] }\end{array}$ & & & & \\
\hline 1 & \multicolumn{2}{|c|}{$\begin{array}{c}\text { без добавки } \\
\text { [without additive] }\end{array}$} & 0.36 & - & & 57 \\
\hline 2 & \begin{tabular}{|c|} 
бинарная добавка \\
[binary additive] \\
«Melflux + ПЭГ» $0.8 \%$ \\
\end{tabular} & $\begin{array}{c}\text { кварцевый } \\
\text { песок } \\
\text { [quartz sand] }\end{array}$ & 0.20 & 44 & 2280 & 130 \\
\hline 3 & \begin{tabular}{|c|} 
бинарная добавка \\
[binary additive] \\
«Melflux + ПЭГ» $0.8 \%$ \\
\end{tabular} & $\begin{array}{c}\text { зола ТЭЦ } \\
\text { [ash of thermal } \\
\text { power station] }\end{array}$ & 0.21 & 42 & 2170 & 98 \\
\hline 4 & «Кратасол ПФМ» 0.8 \% & $\begin{array}{c}\text { вулканический } \\
\text { пепел } \\
\text { [volcanic ash] }\end{array}$ & 0.25 & 30 & 2205 & 115 \\
\hline 5 & «Кратасол ПФМ» 0.8 \% & $\begin{array}{c}\text { вулканический } \\
\text { туф } \\
\text { [volcanic tuff] }\end{array}$ & 0.25 & 30 & 2210 & 118 \\
\hline
\end{tabular}




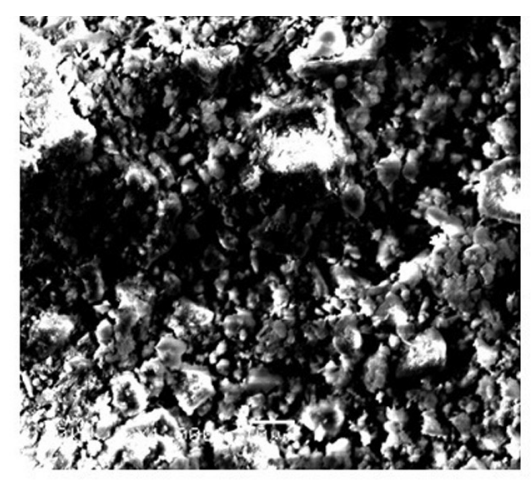

$a$

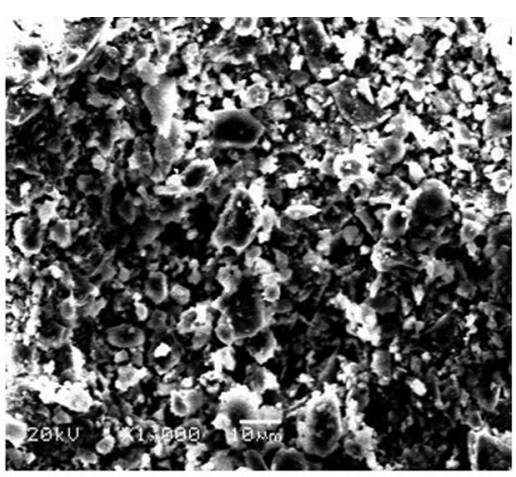

b

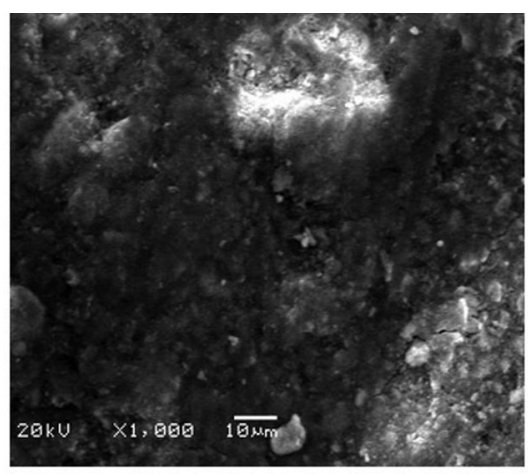

$c$

Рис. 8. Микроструктура цементного камня с органоминеральными добавками различного вида: $a$ ) без добавок; b) с добавками («Melflux» + ПЭГ + зола ТЭЦ); c) с добавками («Melflux» + ПЭГ + кварцевый песок), увеличение $\times 1000$

[Fig. 8. Microstructure of cement stone with organomineralic additives of various types: $a$ ) without additives; $b$ ) with additives («Melflux» + PEG + ash); $c$ ) with additives («Melflux» + PEG + quartz sand) increase $\times 1000]$

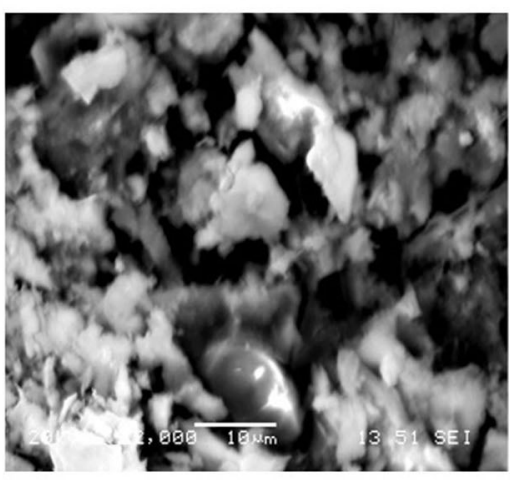

$a$

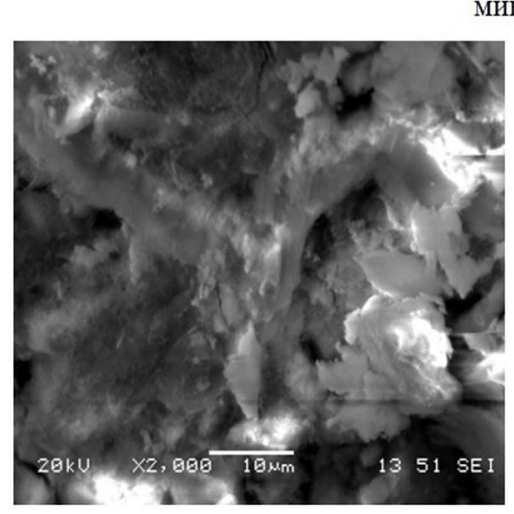

$b$ микропористость (microporosity)

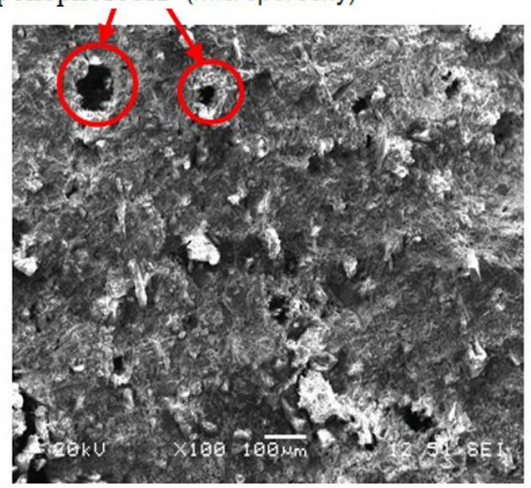

c

Рис. 9. Структура цементного камня модифицированного органоминеральными добавками при различном увеличении: $a)$ без добавок $(\times 2000) ; b)$ с добавкой («Кратасол ПФМ» + вулканический туф) $(\times 2000)$;

c) с добавкой («Кратасол ПФМ» + вулканический туф) $(\times 100)$

[Fig. 9. The structure of cement stone modified with organomineralic additives at different magnification: $a$ ) without additives (Ч 2000); $b$ ) with an additive ("Kratasol PFM“+ volcanic tuff) $(\times 2000) ; c$ ) with an additive ("Kratasol PFM" + volcanic tuff $(\times 100)]$

\section{ЗАКЛЮЧЕНИЕ}

Представленные физико-химические подходы позволили научно обосновано подойти к разработке эффективных комплексных органоминеральных добавок для регулирования технических свойств бетонных смесей и бетона. Предложена классификация минеральных компонентов и разработанная на ее основе система факторов, определяющих эффективность органоминеральных добавок. Предположения о влиянии свойств минеральных компонентов на структурообразование цементного камня позволили установить связь результатов физико-механических испытаний цементного камня с его микроструктурой и свойствами минеральных компонентов. Показана возможность расширения сырьевой базы органоминеральных добавок путем использования местных и доступных минеральных компонентов, а также повышения эффективности синтетических химических компонентов добавок за счет частичного замещения поликарбоксилатного пластификатора на более доступное химическое сырье. Разработанные органоминеральные добавки позволяют модифицировать структуру цементного камня и улучшать физико-технические свойства бетонов.

Работа выполнена при финансовой поддержке РФФИ, грант №18-29-19033 мк 


\section{СПИСОК ЛИТЕРАТУРЫ}

1. Баженов Ю. М. Демьянова В. С., Калашников В. И. Модифииированные высококачественные бетоны. М.: АСВ, 2006, 368 с.

2. Каприелов С. С., Травуш В. И., Карпенко Н. И. и др. // Строительные материаль, 2006, № 10, c. 8-12.

3. Шатов А. Н. // Бетон и железобетон, 2013, № 1, с. 7-9.

4. Шейнфельд А. В. // Бетон и железобетон, 2014, № 3, с. 16-21.

5. Burgos-Montes O. Palacios M., Rivilla P., Puertas F. // Construction and Building Materials, 2012, № 31, pp. 300-309.
6. Перцев В. Т., Ткаченко Т. Ф., Рудаков О. Б. // Конденсированные среды и межфазныле гранищыл, т.18, № 4, 2016, с. 536-544.

7. Перцев В. Т. Управление прочессами раннего структурообразования бетонов: монография. Воронеж: ВГАСУ, 2006, 234 с. $6 \mathrm{c}$.

8. Патент РФ, № 2443648, 2012, Бюл. № 6,

9. Перцев В. Т., Леденев А. А. Разработка эффективных комплексных органоминеральных добавок для регулирования реологических свойств бетонных смесей: монография. Воронеж: ВГАСУ, 2012, 136 с.

\title{
PHYSICAL AND CHEMICAL APPROACHES TO THE DEVELOPMENT OF EFFECTIVE ORGANOMINERAL ADDITIVES FOR CONCRETE
}

\author{
(C) 2018 V. T. Pertsev ${ }^{1}$, A. A. Ledenev ${ }^{2}$, O. B. Rudakov ${ }^{1}$ \\ ${ }^{1}$ Voronezh State Technical University, 14 Moscow ave., 394026 Voronezh, Russia \\ ${ }^{2}$ Military Educational and Scientific Center of the Air Force «N.E. Zhukovsky and Y.A. Gagarin Air Force Academy», \\ $54 A$ Staryh Bol'shevikov str., 394064 Voronezh, Russia \\ e-mail:perec_v@mail.ru \\ Received 15.07.2018
}

\begin{abstract}
The article presents physicochemical approaches to the investigation and development of effective organomineral additives for regulating the properties of concrete mixtures and concrete. The subjects of the research were the physicochemical properties of mineral and organic components of organomineral additives and their influence on the processes of formation of the structure of cement systems. The methodology of the work provides for the development of classification groups of components of organomineral additives and the specification of factors that determine their effectiveness for regulating the properties of concrete mixtures and concretes. It is shown that for mineral components the factors determining the effectiveness of their use in the composition of organomineral additives. are the composition, structure and properties of the surface of particles of the solid phase. The determining factors for organic components are surface-active properties. It is shown that the factors determining the effectiveness of the use of mineral components as additives are the composition, structure and properties of the surface of particles of the solid phase. Determining factors for organic components are surface-active properties.

As a result of the research, the raw materials base of mineral components of organo-mineral additives has been expanded due to the use of natural resources of sedimentary and volcanic origin, as well as some man-made materials. As the organic components of additives the plasticizing surfactants of various nature: a complex plasticizing air-entraining admixture based on polymethylene- $\beta$ naphthalenesulfonates and other air-entraining components, as well as a plasticizing additive based on polycarboxylates were used. The possibility of maintaining the effectiveness of a polycarboxylate plasticizer in the composition of organomineralic additives is shown when it is replaced by up to $30 \%$ for more accessible chemical raw materials having a similar chemical structure.

The application of physicochemical methods of research made it possible to deepen the scientific understanding of the effect of the nature, dispersion, structure and properties of the surface of solid phase particles of mineral components of organomineral additives on the formation of heterogeneous cement systems. The data of electron microscopy showed the relationship between the results of physical and mechanical tests of cement stone with its microstructure and the properties of mineral components. It is established that the application of the developed effective organomineral additives
\end{abstract}




\section{В. Т. ПЕРЦЕВ, А. А. ЛЕДЕНЕВ, О. Б. РУДАКОВ}

allows to modify the structure and improve the physical and technical properties of concrete. Strength of cement stone modified by the developed organomineral additives is $1.7-2.3$ times higher than the strength of cement stone without additives, while in the structure a microporous system favorable for frost resistance is formed.

Keywords: concrete, fine heterogeneous systems, interphase borders, surface-active substances, organomineral additives.

DOI: https://doi.org/10.17308/kcmf.2018.20/580

\section{ACKNOWLEDGMENTS}

The reported study was supported by grant the Russian Foundation for Basic Research, grant No. 18-29-19033 mk

\section{REFERENCES}

1. Bazhenov Yu. M. Demyanova V. S., Kalashnikov V. I. Modified High-Quality Concrete. Moscow, ASV Publ., 2006. 368 p. (in Russ.)

2. Kaprielov S. S., Travush V. I., Karpenko N. I., et al. Building Materials, 2006, no. 10, pp. 8-12. (in Russ.)

3. Shatov A. N. Concrete and Reinforced Concrete, 2013, no. 1, pp. 7-9. (in Russ.)

4. Sheinfeld A. V. Concrete and Reinforced Concrete, 2014, no. 3, pp. 16-21. (in Russ.)
5. Burgos-Montes O., Palacios M., Rivilla P., Puertas F. Construction and Building Materials, 2012, no. 31, pp. 300309. DOI: 10.1016/j.conbuildmat.2011.12.092

6. Pertsev V. T., Tkachenko T. F., Rudakov O. B. Condensed Matter and Interphases, 2016, vol. 18, no. 4, pp. 536-544. (in Russ.)

7. Pertsev V. T. Management of Early Concrete Structure Formation Processes. Voronezh, VGASU Publ., 2006, 234 p. (in Russ.) Russ.)

8. Patent RF, No. 2443648, 2012, Bul. No. 6, 6 p. (in

9. Pertsev V. T., Ledenev, A. A., Development of Effective Complex Organic-mineral Additives to Regulate the Rheological Properties of Concrete Mixtures. Voronezh, VGASU Publ., 2012, 136 p. (in Russ.)
Периев Виктор Тихонович - д. т. н., профессор, профессор кафедры технологии строительных материалов, изделий и конструкций, Воронежский государственный технический университет; тел.: +7(908) 1419555, e-mail: perec_v@mail.ru

Леденев Андрей Александрович - к. т. н., с. н. с., «Военный учебно-научный центр Военно-воздушных сил «Военно-воздушная академия им. профессора Н. Е. Жуковского и Ю. А. Гагарина» (г. Воронеж); тел.: +7(908) 1418539, e-mail: ledenoff@mail.ru

Рудаков Олег Борисович - д. х. н., профессор, заведующий кафедрой химии и химической технологии материалов, Воронежский государственный технический университет; тел.: +7 (980) 5399928, e-mail: rudakov@vgasu.ru
Victor T. Perzev - Dr. Sci. (Eng.), Full Professor, Department of Technology of Construction Materials, Products and Designs, Voronezh State Technical University; tel.:+7 (908) 1419555, e-mail: perec_v@mail.ru

Andrey A. Ledenev - Cand. Sci. (Eng.), Senior Researcher «Military Educational and Scientific Centre of the Air Force N. E. Zhukovsky and Y. A. Gagarin Air Force Academy» (Voronezh); tel.:+7(908) 1418539, e-mail: ledenoff@mail.ru

Oleg B. Rudakov - Dr. Sci. (Chem.), Professor, Head of the Department of Chemistry and Chemical Technology of Materials, Voronezh State Technical University; tel.: +7(980) 5399928, e-mail: rudakov@vgasu.ru 